\title{
Night-shift work duration and breast cancer risk: an updated systematic review and meta-analysis
}

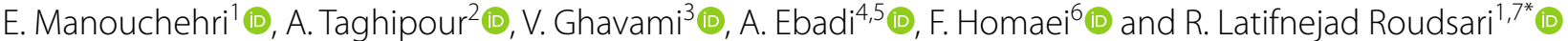

\begin{abstract}
Background: The International Agency for Research on Cancer (IARC) has classified shift work as a possible human carcinogen. The results of systematic on this topic is contradictory. This systematic review and meta-analysis, therefore, aimed to update the current evidence regarding the relationship between night-shift work duration and breast cancer risk.
\end{abstract}

Methods: PubMed, Web of Science, and Scopus as well as reference list of included studies were searched until December 19,2020. Observational case-control or cohort studies investigating the relationship between the duration of night-shift work and breast cancer in women were included, which all quantified night-shift work exposure. All statistical analyses were done by Stata version 11.2.

Results: Our literature search was resulted in retrieval of 4854 publications from which 26 eligible studies with 1,313,348 participants were included in the meta-analyses. The pooled relative risk (RR) and 95\% confidence intervals $(\mathrm{Cls})$ of breast cancer for short-term night-shift workers ( $<10$ years) was $1.13\left(95 \% \mathrm{Cl} 1.03-1.24, \mathrm{p}=0.008, \mathrm{I}^{2}=71.3 \%\right)$, and for long-term night-shift workers ( $\geq 10$ years) was 1.08 ( $95 \% \mathrm{Cl} 0.99-1.17, \mathrm{p}=0.09, \mathrm{I}^{2}=42.2 \%$ ), with moderate to substantial statistical heterogeneity observed in both analyses. The results of subgroup analysis showed that flight attendants with long overnight flights were at an elevated risk of breast cancer, but unmeasured confounders limited these results. The risk of breast cancer in case control studies, adjusted for reproductive factors and family history of breast cancer as well as studies with high quality was increased in both short term and long term night-shift workers.

Conclusions: This systematic review found a positive statistical relationship between night work and breast cancer risk in short-term night-shift workers but no increase was observed in the long-term night-shift workers.

Keywords: Breast cancer, Meta-analysis, Night-shift work, Shift-work, Systematic review

\section{Background}

The most widely identified invasive cancer among women is breast cancer (BC), afflicting one in eight women [1]. $25 \%$ of all cancers and $15 \%$ of deaths in women are related to $\mathrm{BC}[2]$. Not all women run the same risk of $\mathrm{BC}$ during their lives, but specific factors, called risk

\footnotetext{
*Correspondence: latifnejadr@mums.ac.ir; rlatifnejad@yahoo.com ${ }^{1}$ Department of Midwifery, School of Nursing and Midwifery, Mashhad University of Medical Sciences, Mashhad, Islamic Republic of Iran Full list of author information is available at the end of the article
}

factors, increase their chances of contracting the disease. The proportion of diseases that could be prevented by decreased exposure to modifiable risk factors, can help to recognize where and for whom such preventative disease-specific strategies need to be dedicated [3]. Research found that around half of the global cancer burden is the consequence of some modifiable factors including diet, obesity, sedentary lifestyle as well as endocrine disrupting chemicals and can thus be prevented [4]. 
Khakbazan et al. [5] reported that the increase in life expectancy along with the propensity to adopt a western lifestyle has changed BC into a growing public health concern in many developing countries.

An issue taken into account in numerous epidemiological studies over the past decade is the effect of shifts on BC [6]. Shift work refers to a work schedule that is outside the standard 9 am to $5 \mathrm{pm}$, including evening or night shifts, early morning shifts, and rotating shifts [7]. According to a 2009 IARC working group, a night-shift is described as $\geq 3 \mathrm{~h}$ of work between midnight and $5 \mathrm{am}$ [8].

Shift work exists in many industries and factories such as the oil industry, power plants, and iron and steel industries, fields related to medicine, midwifery, and nursing, and fire department, law enforcement, and water, electricity, and telephone services [9]. This type of work can lead to disturbed circadian rhythm, diminished melatonin hormone, and sleep disturbances that affect hundreds of metabolic and physiological processes, including synthesis of hormones, apoptosis, and cell cycle life and trigger tumors such as $\mathrm{BC}$ in the human body $[10,11]$. According to the data collected in 2015, in the sixth EU Survey on Working Conditions, $14 \%$ of the female working population reported working during the night [12].

The disruption in the circadian rhythm following exposure to light at night (LAN) has long been considered as a possible cause of $B C[13,14]$. The shift work, in addition to exposure to LAN, results in irregularities in eating as well as social and familial relationships [15]. Possible mechanisms for carcinogenesis of LAN are suppressed melatonin hormone, reduced immune system following sleep disorder, confusion in the body circadian system, and irregularity in cell proliferation [16].

In 2019, the IARC re-assessed night-shift work (NSW) and described it as a "probable" carcinogen (IARC Group 2A) [17]. However, the results of the systematic reviews and meta-analyses on the relationship between nightshift work and $\mathrm{BC}$ have been contradictory $[18,19]$ and articles are increasingly being published with opposing results in this regard [20-22]. According to a meta-analysis on cohort studies (2015), rotating NSW increased the incidence of $\mathrm{BC}$ by $8.9 \%$, and a positive dose-response relationship was found between NSW and breast tumor incidence [23]. It was found by Wang et al. in a metaanalysis that the risk of female $\mathrm{BC}$ would increase by $3 \%$ following each 5-year increase in NSW exposure [24], which is supported by some other meta-analyses [25-27]. But in other systematic reviews and meta-analyses this relationship has not been reported [19, 28-30]. Kamdar et al. in a meta-analysis of 15 observational studies reported weak evidence to support the association between NSW with increased BC risk [29].

Moreover, the duration of NSW has not been considered by some meta-analyses [31]. Due to the growing worldwide prevalence of shift work, the great economic burden of $\mathrm{BC}$, and the large number of articles with inconsistent results, the present review aimed to investigate the relationship of night-shift work and its duration with $\mathrm{BC}$ risk through a systematic review and meta-analysis of the existing observational studies. In addition, in the present study, the subgroup analysis for selected variables, and a review of past meta-analyses is carried out.

\section{Methods \\ Search strategy}

Preferred Reporting Items for Systematic Reviews and Meta-Analyses (PRISMA) guidelines were adopted for reporting this systematic review and meta-analysis. PubMed, Web of Science, Google Scholar, and Scopus were browsed up to December 19, 2020. There was no limit on the initial date applied. The key words employed to identify the studies were: "shift work" OR "night work" OR "night-shift work" OR "rotating-shift work" AND "breast cancer" OR "breast carcinoma" OR "breast neoplasm". Boolean operators (AND, OR), truncation, and $\mathrm{MeSH}$ terminology were used appropriately for the systematic identification of data (Table 1).

\section{Inclusion and exclusion criteria}

Studies were included in the review if they had the following criteria (1) were peer-reviewed case-control, observational nested case-control, or cohort studies (2) quantified NSW in all job categories including work

Table 1 Strategy for systematic searches of the published literature

\begin{tabular}{ll}
\hline Search & Most recent queries \\
\hline$\# 1$ & Search "Breast cancer"[All Fields] OR "Breast neoplasm"[MeSH Terms] OR "breast \\
$\# 2$ & carcinoma"[All Fields] OR "breast tumor"[All Fields]" \\
$\# 3$ & "night shift work"[All Fields]) OR "night work"[All Fields] OR "shift work"[All Fields]) \\
$\# 4$ & $\# 1$ AND \#2 \\
\hline
\end{tabular}


on domestic and/or intercontinental overnight flights), (3) provided risk ratios, odds ratios, hazard ratios, and 95\% CIs for BC incidence confirmed by histopathology or through data available from Cancer Registry in females aged at least 18 years old. There was no restriction regarding country, race, publication language, and date. Excluded studies were (1) studies that reported the duration of night-shift work as "ever vs never" (2) those involving nighttime light exposure that was involuntary or non-work related, sleep duration, or subjects included with recurrent $\mathrm{BC}$, and (3) studies that their full texts were not accessible. Identified studies using the Endnote X8.1 software were retrieved and managed.

\section{Study selection}

At first, the titles and abstracts and then, the full texts of the studies were reviewed, separately, by two authors, and any inconsistency was discussed by a third author. There was only one case of disagreement regarding the inclusion of articles with the same population (entry of the most recent articles or articles with a larger population). Hand searching was carried out to identify further relevant studies.

\section{Outcome variable}

The outcome variable of this study was breast cancer, which was defined as having positive diagnosis of $\mathrm{BC}$ based on the medical records or through data available from cancer registry.

\section{Quality (risk of bias) assessment}

Two researchers (EM and an assistant) independently evaluated the methodological quality of individual studies using the Newcastle-Ottawa Quality Assessment Scale. Newcastle-Ottawa Scale (NOS) was examined for Cohort and case-control studies in terms of interrater reliability and construct validity in a previous study which reported a high degree of agreement across its domains [32]. The star system with a maximum of nine stars (scoring 0 to 9) was adopted by NOS, which was categorized into three parts: participant selection, comparability of study groups, exposure assessment/outcome evaluation [33]. The stars were classified as follows: 7-9 stars showed high quality, 4-6 stars meant a medium quality and 0-3 stars indicated a low quality [34].

\section{Data extraction}

Relevant variables included the first author's name, year of publication, geographic location of participants, type of study (nested case-control, case-control or cohort studies), occupation of participants, years of follow up, source of data about outcome and exposure, definition of exposure, number of $\mathrm{BC}$ cases and controls (for case-control studies), cohort size (for cohort studies), risk estimates and 95\% CIs for $\mathrm{BC}$ incidence and nightshift work duration category, source of funding and confounders for which risk estimates were adjusted. Data extraction was done separately by two researchers (EM and an assistant) using duplicate spreadsheets for validating the data extraction process. "Night shift work" was the main exposure variable, and the absence of night work was the preferred control group.

\section{Quantification and categorization of NSW}

The duration of NSW exposure was reported in the studies included in this systematic review as an open ( $\geq 30$ years) or closed (15-29 years) time periods. Using the midpoint for closed time periods and the minimum points for open time periods, single numeric values was assigned to each one. According to the assumption that a longer duration of NSW may be correlated with a higher incidence of $\mathrm{BC}$, NSW exposure was divided into two groups: short-term ( $<10$ years) and long-term $(>10$ years) NSW. After rounding the median of all allocated range values, the cutoff point between short-term and long-term NSW of 10 years was obtained [29].

\section{Subgroup analyses}

Subgroup analyses were carried out by study type (nested case-control, case-control or cohort), occupation (nurses, flight attendants, or others), geographical area (Europe, North America, Asia and, Oceania), adjustment of studies for reproductive factors (yes or no), as well as a family history of $\mathrm{BC}$ (yes, no), quality category (high or moderate) and reporting the source of funding (yes or no) regarding short-term and long-term exposures separately.

\section{Statistical methods}

To test the relationship between NSW and BC, risk ratios (RRs) were used. Adjusted risk assessments were preferred over crude measures where available. Then, pooled risk estimates were determined using randomeffect models for the short-term and long-term NSW groups that were used due to substantial heterogeneity $(\mathrm{p}<0.05)$ present in some studies. In studies that have reported multiple RRs for NSW duration, if there was more than one stratification in each short- or long-term category, we used the method of combining effect sizes across multiple comparisons within individual studies introduced by Borenstein et al. [35]. Using the $\times 2$ and I2 statistics, statistical heterogeneity between studies was assessed. Heterogeneity was considered to be high if the $\mathrm{I}^{2}$ statistic was greater than $50 \%$ [36]. In order to further investigate the risk ratio in the study population, subgroup analysis was performed. We used funnel 
plots, Egger [37] and Begg [38] tests for assessing the

publication bias. Statistical significance was considered
as $\mathrm{p}<0.05$. All analyses were conducted using Stata ver-

publication bias. Statistical significance was considered
as $\mathrm{p}<0.05$. All analyses were conducted using Stata version 11.2 (StataCorp, College Station, Texas).

\section{Results}

\section{Selection of studies}

Details of the literature review and study selection process are shown in Fig. 1. The search yielded 4872 articles, of which 1888 were duplicate records. We included all the articles in previous meta-analyses $[18,25,29]$ in of Science $=610$, PubMed $=114$

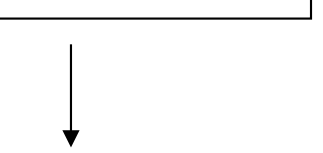

Studies included in systematic review $(\mathrm{n}=43)$
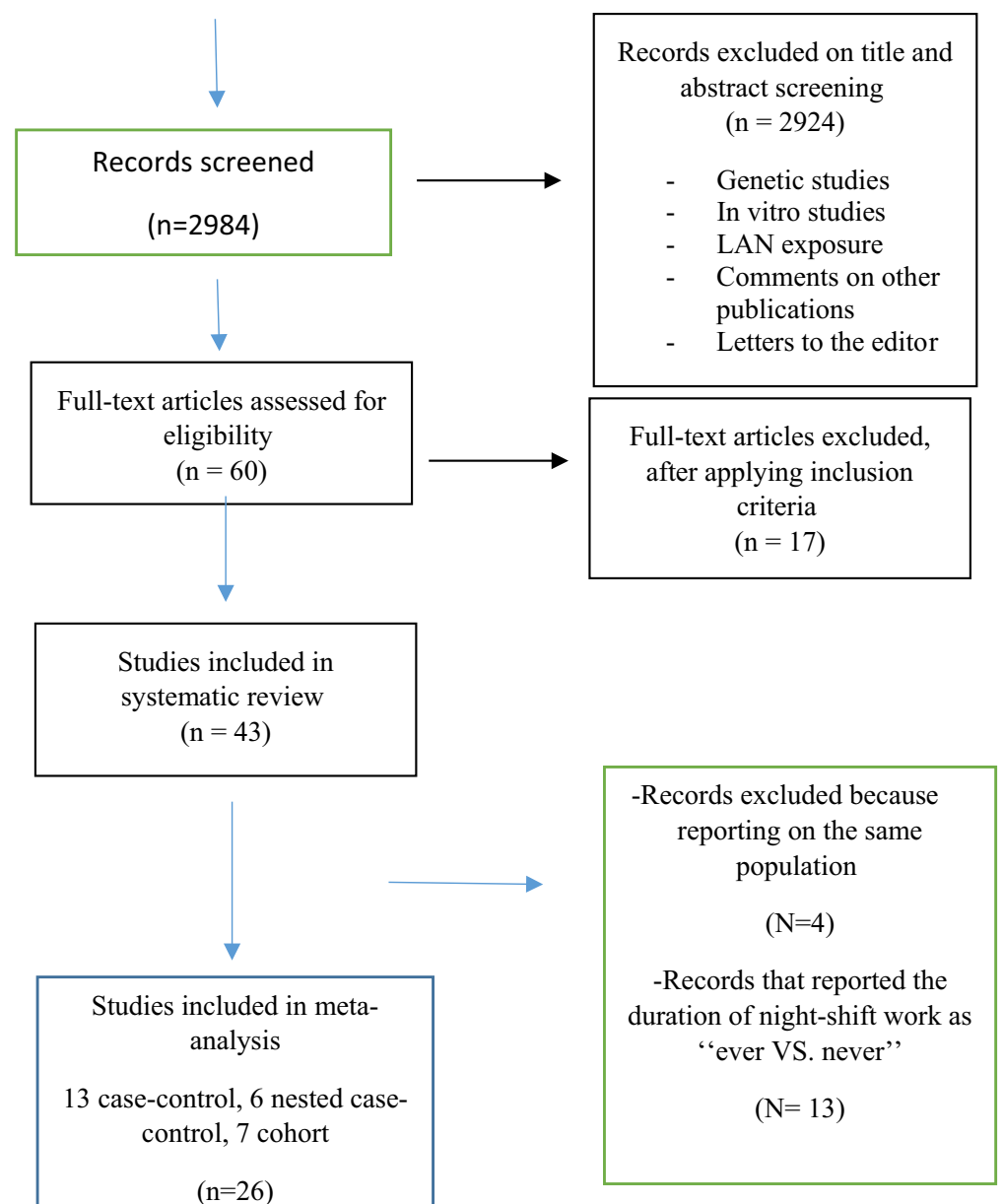
$(\mathrm{n}=2984)$

Additional studies identified through other sources $(\mathrm{n}=18)$

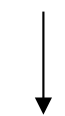

Records after duplicates removed
Records excluded because orting on the same ation

$$
(\mathrm{N}=4)
$$

$$
(\mathrm{N}=13)
$$

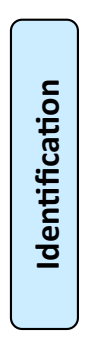

Records identified through database searching

Google scholar $=4050$, Scopus $=80$, Web

$\mathrm{N}=4854$
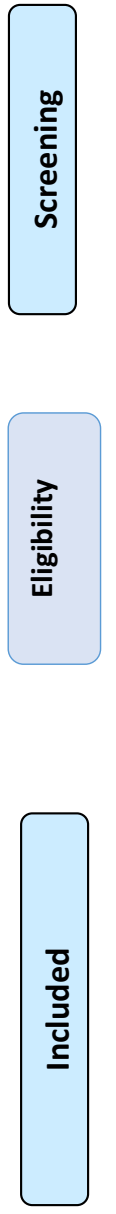

Fig. 1 PRISMA Flowchart of the study selection process 
the present study. After review of abstracts 2924 studies were excluded for the following reasons: being focused on genetic issues, being conducted as In vitro study, and reporting LAN exposure. Also, comments on other publications and letters to the editor were excluded. We reviewed 60 full-text articles, of which 17 were excluded from the study because they did not meet the inclusion criteria, while 43 satisfied all the inclusion criteria. Regarding cohorts with several reports, we used data from the publication with the longest follow-up, hence the exclusion of four articles [6, 39-41]. 13 studies reported the duration of NSW exposure as "ever" also were excluded [42-54]. The present meta-analysis included 26 studies: six nested case-control [20, 21, 5558] (Table 2), 13 case-control [16, 22, 59-69] (Table 2) and seven cohort [28, 70-75] studies (Table 3 ).

\section{Identification and description of studies}

Overall, the nested case-control studies included a total of $3574 \mathrm{BC}$ cases and 10,530 controls, the case-control studies comprised a total of 18,275 BC cases and 19,341 controls, and the cohort studies consisted of a total of 23,492 BC cases from an at-risk population of 1,261,628 individuals. The study population included individuals pulling rotating or overnight shifts, including nurses $[40,41,58,67,68,73]$, flight attendants $[56,57]$, military employees [20], textile workers [21], radio and telegraph operators [55] and women in different public and private companies [16, 22, 59-66, 69-72, 74, 75]. Geographically, 17 of the 26 studies belonged to European countries [16, $20,28,55-59,61,64-68,70-72]$, five to the USA [60, 62, $63,73,75]$, three to Asia $[21,69,74]$ and one to Oceania [22] (Table 4). One or more BC risk factors were adjusted in all but one study [57] (Table 2). All articles were published during 1996-2020, and most were published in 2013 [22, 59, 62, 66, 68]. All included articles were written in English and we did not find any article in another language.

\section{Quality assessment}

Twenty one studies had "high" quality assessment scores $[16,20,22,28,58-70,72-75]$ and $5[21,55-57,71]$ articles had moderate quality assessment scores (Table 4). The quality of studies ranged from 6 to 8 points, with a median of 7 (Additional file 1: Appendix). The weakest part of the articles according to the NOS tool was the exposure/outcome domain. Three articles (11.5\%) in the exposure/outcome domain had a high risk of bias [70, 73, 75]. The researchers gave similar scores to the articles.

\section{Exposure measurement}

Measurement and stratification of NSW exposure duration varied substantially between the studies. Twenty six studies provided risk estimates with a median exposure duration of 5 years (IQR 4-6) falling under the shortterm NSW group (<10 years) [16, 20-22, 28, 55-75]. Seventeen studies provided risk estimates in the longterm NSW group ( $\geq 10$ years), with a median exposure duration of 17.5 years (IQR, 15-23) [20-22, 28, 55, 58, 62, 64-66, 69-75]. We produce a single pooled shortor long-term risk estimate for the 22 studies with multiple risk estimates that fall under either the short- or long-term exposure categories [16, 20-22, 28, 55, 58-60, $62-68,70-75]$. Regarding the two studies that considered intercontinental flight hours as night time work [56, 57], we considered 5,000 flight hours equivalent to almost 5 years of NSW, based on published labor reports [76]. Also in another study, years of work on a ship and cross time zones were considered as NSW [55].

\section{Primary $\mathrm{BC}$ risk analyses}

In the cases of short-term NSW ( $<10$ years), BC risk was significantly increased $(R R=1.13,95 \%$ CI 1.03-1.24, $\mathrm{p}=0.008, \mathrm{I}^{2}=71.3 \%$ and $\mathrm{p}<0.001$ ) (Fig. 2; Table 4) but the increase was not significant in the cases of long-term NSW ( $\geq 10$ years) $(R R=1.08,95 \%$ CI $0.99-1.17, \mathrm{p}=0.09$, $\mathrm{I}^{2}=42.2 \%$ and $\mathrm{p}=0.03$ ) (Fig. 3; Table 4), with moderate to significant statistical heterogeneity observed in both groups.

\section{Subgroup analyses}

The association of NSW with BC was assessed in subgroups including study type (nested case-control, casecontrol or cohort), occupation (nurses, flight attendants, or others), geographical area (Europe, North America, Asia and Oceania), adjustment of studies for reproductive factors (yes or no), as well as family history of $\mathrm{BC}$ (yes, no) , quality category (high or moderate) and reporting the source of funding (yes or no) regarding short-term and long-term exposures separately. In some of the subgroups, a significantly increased BC risk was observed in women involved in NSW (Table 4).

\section{For short-term versus never NSW the results were as follows}

A statistically significant association was found between short-term NSW and risk of BC in the case-control subgroup $(R R=1.25,95 \%$ CI 1.08-1.44). In flight attendants, the short-term NSW increased the risk of $\mathrm{BC}(\mathrm{RR}=3.94$, 95\% CI 1.42-10.91). There was no significant association identified between short-term NSW and risk of BC in North America (Table 4). The subgroup analysis showed a significant association between short-term NSW and $\mathrm{BC}$ risk in the subgroups adjusted for the status of reproductive ( $R R=1.15,95 \%$ CI 1.05-1.27) and family history $(\mathrm{RR}=1.11,95 \%$ CI 1.03-1.2). A significant relationship was further observed between short-term NSW and BC 


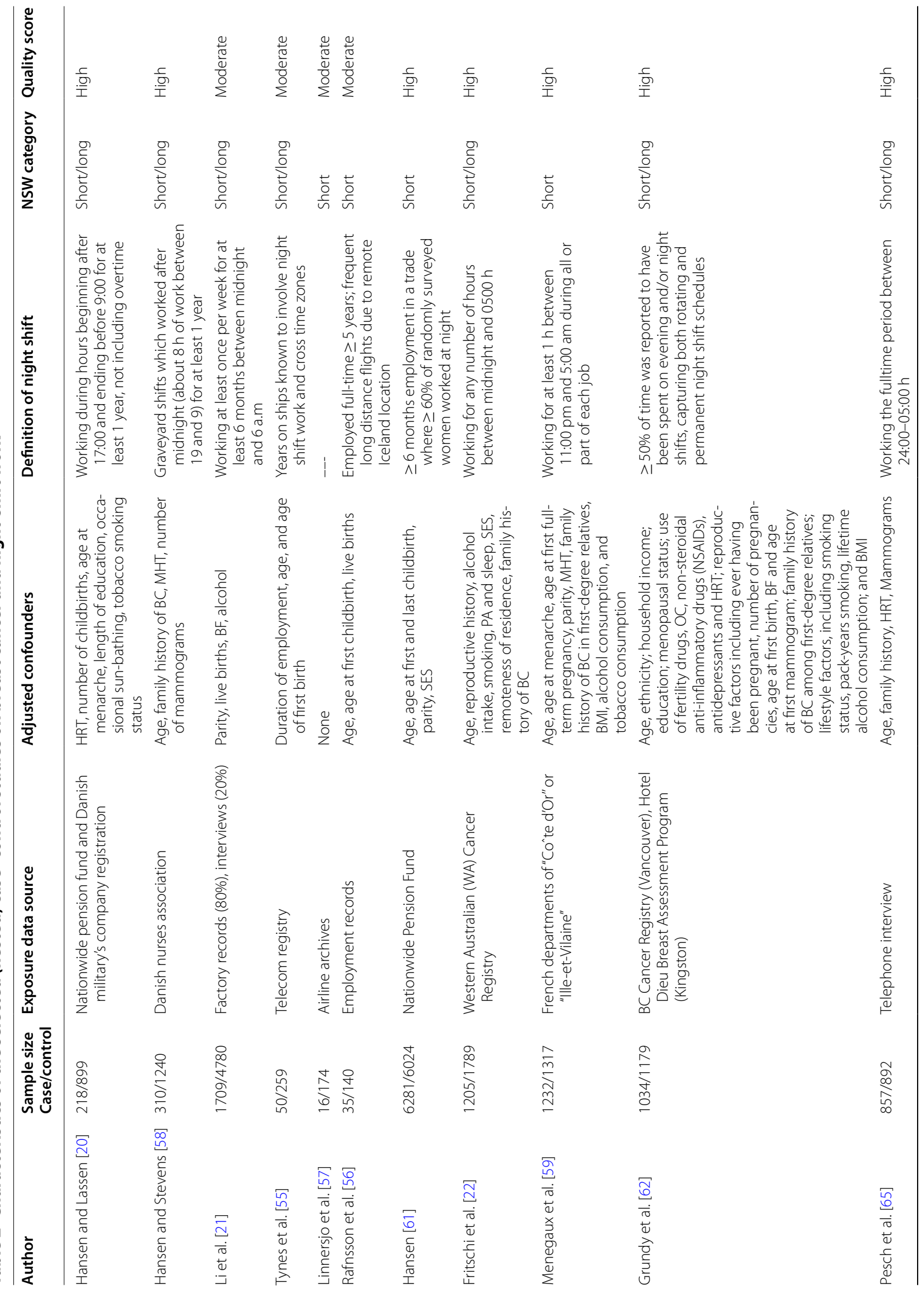




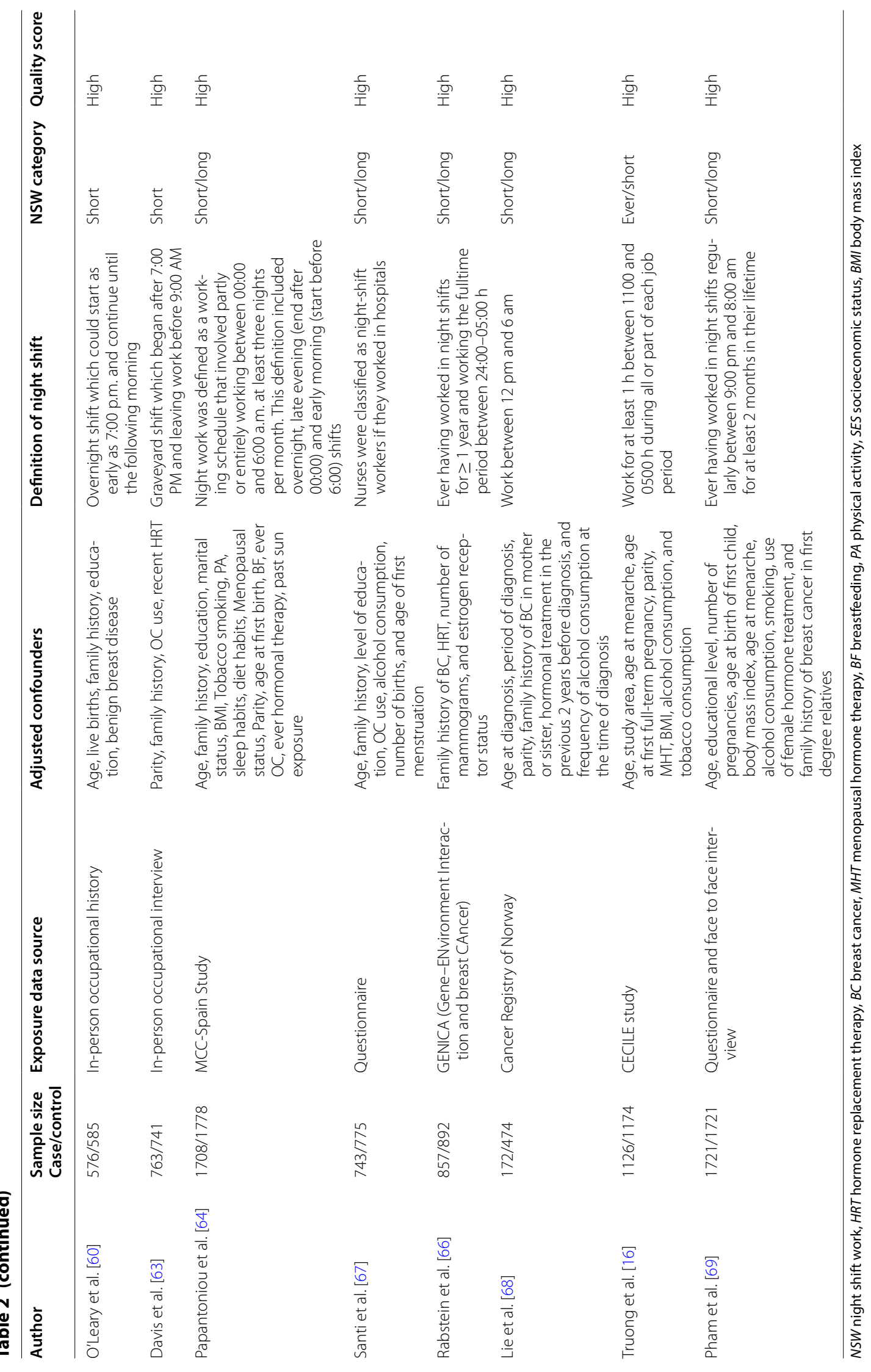




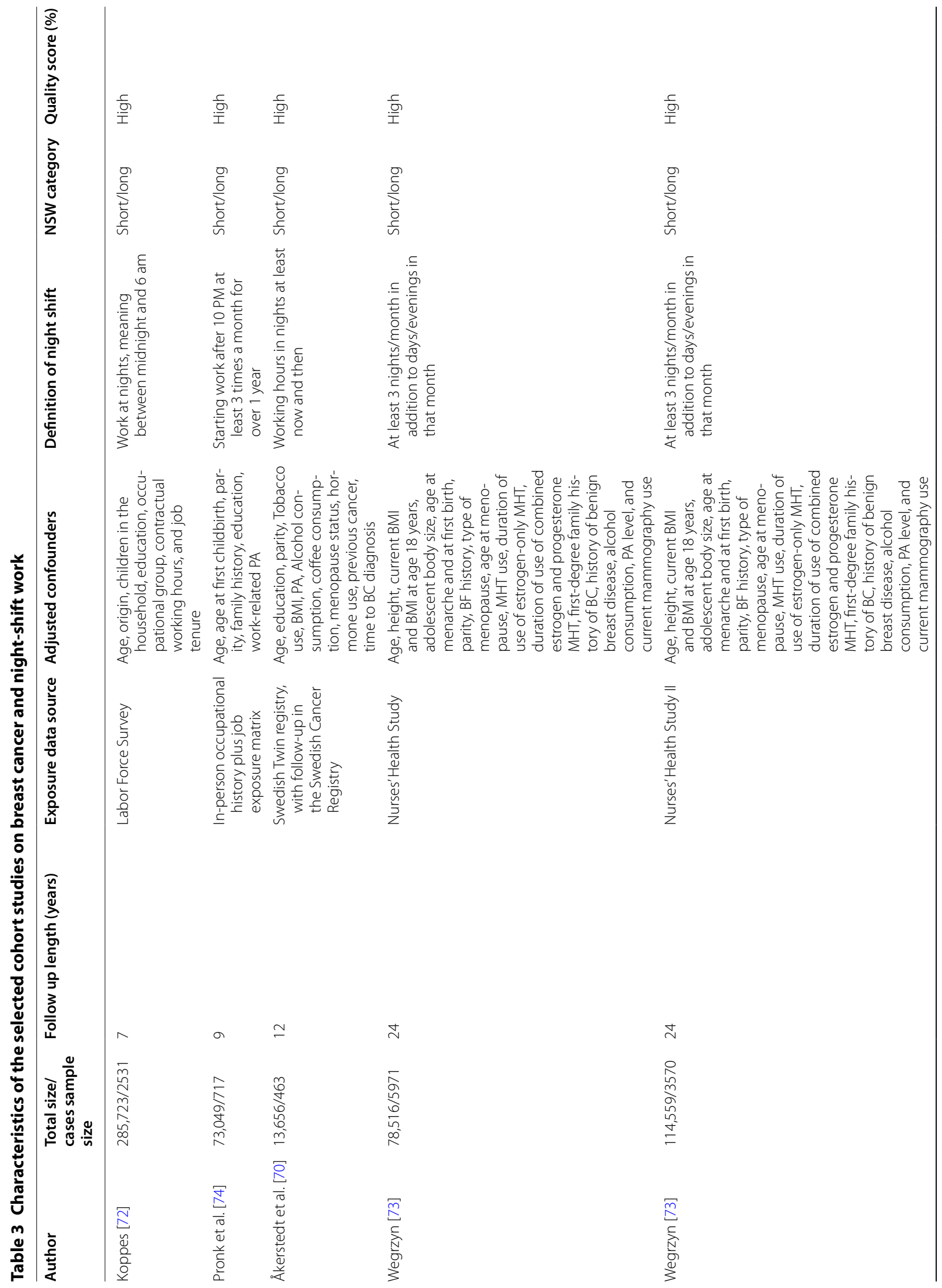




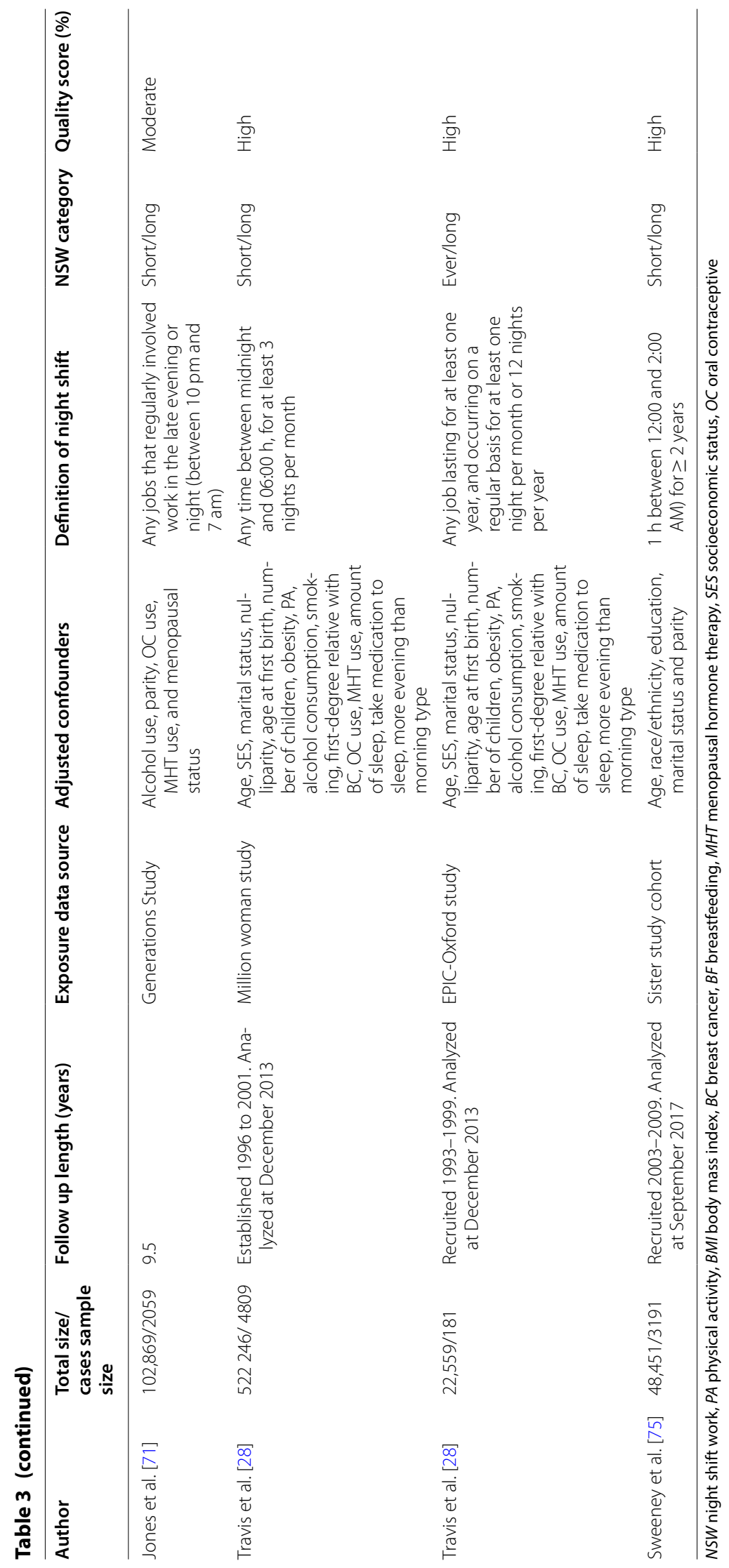


Table 4 Pooled risk estimates for breast cancer and heterogeneity analysis from adjusted risk estimates

\begin{tabular}{|c|c|c|c|c|c|c|c|c|}
\hline \multirow[t]{2}{*}{ Factors stratified } & \multicolumn{4}{|c|}{ Short-term ( $<10$ years) versus never night-shift work } & \multicolumn{4}{|c|}{ Long-term ( $\geq 10$ years) versus never night-shift work } \\
\hline & No. of studies & $\mathrm{RR}(95 \% \mathrm{Cl})$ & $R^{2}, \%$ & P value & No. of studies & RR $(95 \% \mathrm{Cl})$ & $R^{2}, \%$ & P value \\
\hline All studies & $26(16,20-22,28,55-75)$ & $1.13(1.03-1.24)$ & 73.4 & 0.001 & $\begin{array}{l}17(20-22,28,55,58,62 \\
\quad 64-66,69-75)\end{array}$ & $1.08(0.99-1.17)$ & 42.2 & 0.028 \\
\hline \multicolumn{9}{|l|}{ Study type } \\
\hline Nested case-control & $6(20,21,55-58)$ & $1.40(0.9-2.19)$ & 66.2 & 0.011 & $4(20,21,55,58)$ & $1.5(0.86-2.66)$ & 84.7 & 0.001 \\
\hline Case-control & $13(16,22,59-69)$ & $1.25(1.8-1.44)$ & 59.8 & 0.003 & $6(22,62,64-66,69)$ & $1.22(1.02-1.46)$ & 0 & 0.819 \\
\hline Cohort & $7(28,70-75)$ & $1.02(0.97-1.06)$ & 0 & 0.636 & $7(28,70-75)$ & $1.01(0.95-1.07)$ & 0 & 0.706 \\
\hline \multicolumn{9}{|l|}{ Occupation } \\
\hline Flight attendants & $2(56,57)$ & $3.94(1.42-10.91)$ & 0 & 0.806 & 0 & - & - & - \\
\hline Nurses & $4(58,67,68,73)$ & $1.14(0.99-1.3)$ & 71.6 & 0.007 & $2(58,73)$ & $1.25(0.92-1.70)$ & 81.6 & 0.004 \\
\hline Other & $\begin{array}{l}19(16,20-22,50,55 \\
59-66,69-72,74,75)\end{array}$ & $1.09(0.97-1.22)$ & 68.8 & 0.001 & $\begin{array}{l}14(20-22,28,55,62 \\
\quad 64-66,69-72,74,75)\end{array}$ & $1.03(0.95-1.11)$ & 17.9 & 0.248 \\
\hline \multicolumn{9}{|l|}{ Geographic area } \\
\hline Europe & $\begin{array}{l}17(16,20,28,55-59,61 \\
64-68,70-72)\end{array}$ & $1.19(1-1.41)$ & 72.9 & 0.001 & $\begin{array}{l}10(20,28,55,58,64-66 \\
70-72)\end{array}$ & $1.21(1.02-1.44)$ & 54.4 & 0.016 \\
\hline North America & $5(60,62,63,73,75)$ & $1.04(0.96-1.13)$ & 39.1 & 0.145 & $3(62,73,75)$ & $1.05(0.94-1.16)$ & 0 & 0.417 \\
\hline Asia & $3(21,69,74)$ & $1.04(0.93-1.17)$ & 0 & 0.7 & $3(21,69,74)$ & $0.94(0.84-1.07)$ & 16.2 & 0.303 \\
\hline Oceania & $1(22)$ & $1.25(1.01-1.55)$ & - & - & $1(22)$ & $1.05(0.78-1.41)$ & - & - \\
\hline \multicolumn{9}{|c|}{$\begin{array}{l}\text { Adjusted for reproductive } \\
\text { variables }\end{array}$} \\
\hline Yes & $\begin{array}{l}24(16,20-22,28,55-71 \\
\quad 73,74)\end{array}$ & $1.15(1.05-1.27)$ & 72.6 & 0.001 & $\begin{array}{c}15(20-22,28,55,58,62 \\
64-66,69-71,73,74)\end{array}$ & $1.1(1-1.21)$ & 47.9 & 0.015 \\
\hline No & $2(72,75)$ & $0.94(0.75-1.17)$ & 19 & 0.266 & $2(72,75)$ & $0.95(0.76-1.19)$ & 0 & 0.899 \\
\hline \multicolumn{9}{|l|}{ Adjusted for family $H x$} \\
\hline Yes & $\begin{array}{c}18(16,22,28,58-60 \\
62-69,71,73-75)\end{array}$ & $1.11(1.03-1.2)$ & 48.7 & 0.009 & $\begin{array}{l}12(22,28,58,62,64-66 \\
69,71,73-75)\end{array}$ & $1.1(1-1.2)$ & 40.2 & 0.059 \\
\hline No & $\begin{array}{l}8(20,21,55-57,61,70 \\
72)\end{array}$ & $1.16(0.83-1.62)$ & 83.5 & 0.001 & $5(20,21,55,70,72)$ & $1.06(0.84-1.34)$ & 44.1 & 0.128 \\
\hline \multicolumn{9}{|c|}{ Adjusted for confounders } \\
\hline Yes & $\begin{array}{l}25(16,20-22,28,55 \\
57-75)\end{array}$ & $1.13(1.03-1.23)$ & 71.9 & 0.001 & $\begin{array}{l}17(20-22,28,55,58,62 \\
64-66,69-75)\end{array}$ & $1.08(0.99-1.17)$ & 42.2 & 0.028 \\
\hline No & $1(57)$ & $3.27(0.54-19.85)$ & - & - & 0 & - & - & - \\
\hline \multicolumn{9}{|l|}{ Quality category } \\
\hline High & $\begin{array}{l}21(16,20,22,28,58-70, \\
\quad 72-75)\end{array}$ & $1.15(1.04-1.26)$ & 73.8 & 0.001 & $\begin{array}{l}14(20,22,28,58,62 \\
64-66,69,70,72-75)\end{array}$ & $1.1(1-1.21)$ & 41.4 & 0.042 \\
\hline Moderate & $5(21,55-57,71)$ & $1.05(0.78-1.40)$ & 50.2 & 0.09 & $3(21,55,71)$ & $1.01(0.82-1.24)$ & 45.3 & 0.161 \\
\hline \multicolumn{9}{|l|}{ Source of funding } \\
\hline Low risk & $\begin{array}{l}22(16,20-22,28,56-60 \\
\quad 62,64-73,75)\end{array}$ & $1.08(1.01-1.17)$ & 50.2 & 0.003 & $\begin{array}{c}15(20-22,28,58,62 \\
64-66,69-73,75)\end{array}$ & $1.09(1-1.2)$ & 46 & 0.02 \\
\hline Unclear & $4(55,61,63,74)$ & $1.36(0.97-1.91)$ & 79.9 & 0.002 & $2(55,74)$ & $1.02(0.66-1.58)$ & 16.7 & 0.273 \\
\hline
\end{tabular}

Cl confidence interval

$P$ values represent heterogeneity

risk in high quality studies $(\mathrm{RR}=1.15,95 \% \mathrm{CI} 1.04-1.26)$ (Table 4).

\section{In regard to long-term versus never NSW, the results were as follows}

There was a significant association between long-term NSW and $\mathrm{BC}$ risk in case-control studies $(\mathrm{RR}=1.22$, 95\% CI 1.02-1.46). Stratification of the studies by occupation revealed that there was no significant relationship between long-term NSW and risk of BC $(\mathrm{RR}=1.03,95 \% \mathrm{CI} 0.95-1.11)$. As far as the geographic area is concerned, the association between long-term NSW and risk of $\mathrm{BC}$ was significant only in Europe $(\mathrm{RR}=1.21,95 \%$ CI 1.02-1.44) (Table 4). Also, there was a significant association between long-term night-shift work and $\mathrm{BC}$ risk in the subgroups adjusted for the status 


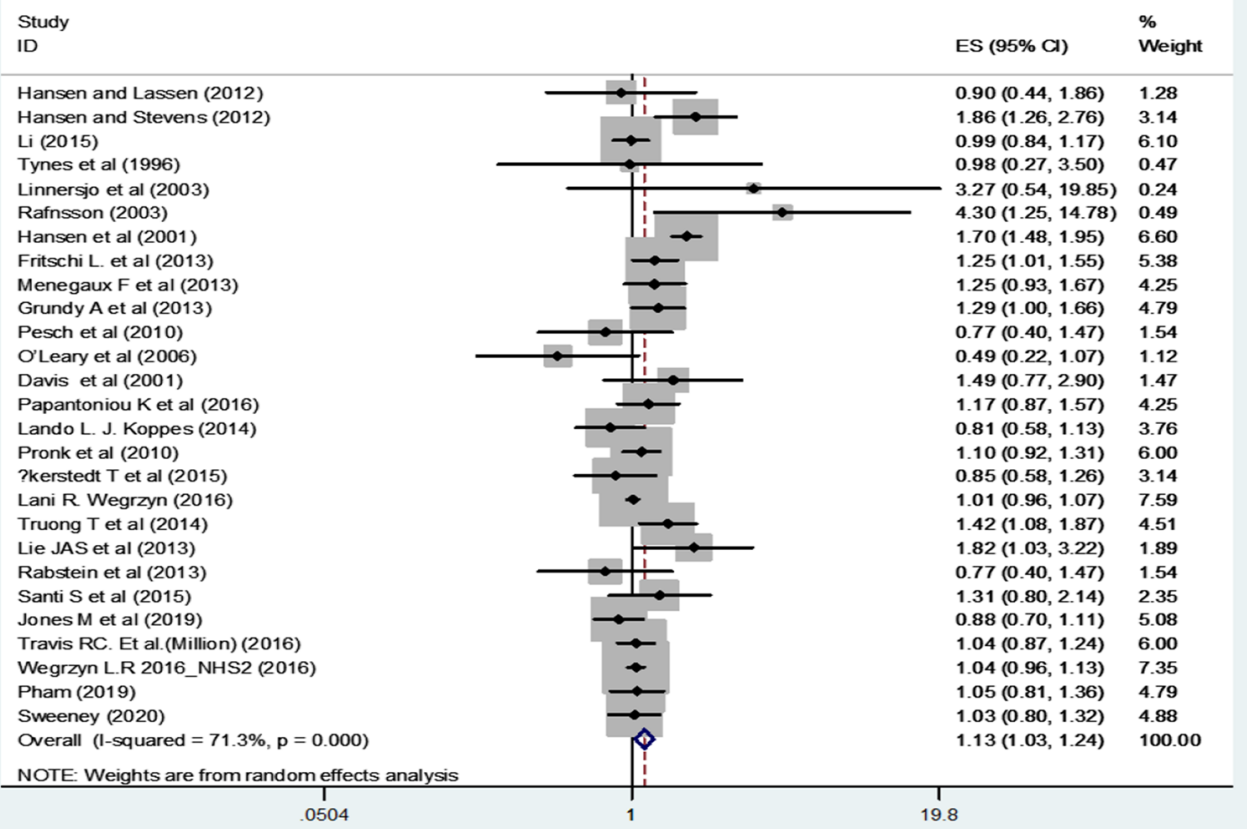

Fig. 2 Forest plot showing risk of breast cancer for short-term ( $<10$ years) versus never night shift workers

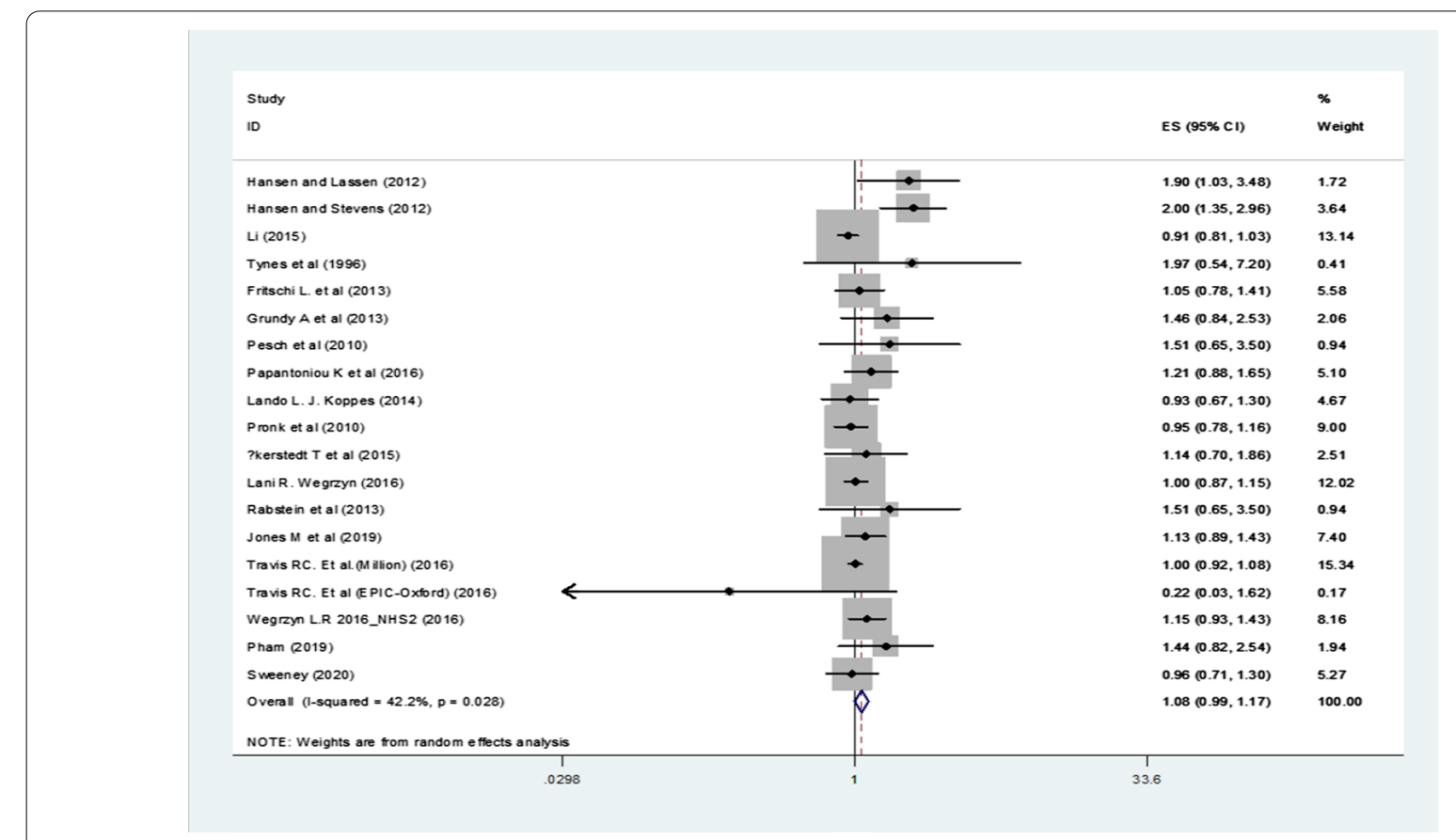

Fig. 3 Forest plot showing risk of breast cancer for long-term ( $\geq 10$ years) versus never night shift workers 
of reproductive factors $(R R=1.1,95 \% \mathrm{CI} 1-1.21)$ and positive family history of $\mathrm{BC}(\mathrm{RR}=1.1,95 \% \mathrm{CI} 1-1.2)$. A significant relationship was also observed between shortterm night-shift work and BC risk in high quality studies $(\mathrm{RR}=1.1,95 \%$ CI 1-1.21) (Table 4).

\section{Heterogeneity analysis}

To evaluate heterogeneity between included studies the $\mathrm{X}^{2}$ and $\mathrm{I}^{2}$ statistics were used. Overall, the heterogeneity in the short-term NSW was high $\left(\mathrm{I}^{2}=73.4 \%\right)$. Also, heterogeneity was observed in six subgroup analyses (i.e., case-control studies, other occupations, adjustment for reproductive factors and confounders, high quality studies and, low risk studies for source of funding) (Table 4).

The heterogeneity in the long-term NSW was low $\left(\mathrm{I}^{2}=42.2 \%\right)$. In the long-term NSW group, the heterogeneity was removed in case-control studies, cohort studies and, the studies from North America $\left(\mathrm{I}^{2}=0.0 \%\right)$. In this group, heterogeneity was observed in three subgroup analyses (i.e., nested case-control studies, nurses and, European countries.)

\section{Publication bias}

Egger and Begg tests and the funnel plot for short-term (Additional file 1: Appendix) did not provide significant evidence on the publication bias in the short NSW exposure group (Egger: $\mathrm{p}=0.56$; Begg: $\mathrm{p}=0.35$ ). However, Egger and Begs tests (Egger: $\mathrm{p}=0.003$; Begg: $\mathrm{p}=0.09$ ) and the funnel plot for long-term (Additional file 1: Appendix) provided evidence for the publication bias. For further assessment on publication bias in long-term night-shift workers, we ran trim and fill method [77, 78]. This technique enables us to investigate the potential effect of publication bias. It employs an algorithm to impute potentially missing studies for the reason of publication bias and generates a funnel plot that includes both the observed studies and the imputed studies, so that when the imputed studies are included, the researcher can see how the effect size changes. This approach does not require any assumptions about the process leading to publication bias, provides an estimation of the number of missing studies, and also, based on the filled studies, provides an 'adjusted' estimated impact for the publication bias $[77,78]$. In this imputation method on our study, five hypothetically missing studies were imputed, as square shapes, in funnel plot (Additional file 1: Appendix). Based on the results of trim and fill imputation method the 'adjusted' point estimate is almost close to the $(R R=1.02$, 95\% CI 0.91-1.15). It is worth noting that despite the lack of publication bias in short-term night-shift workers, we ran trim and fill method, and obviously no missing study was imputed (Additional file 1: Appendix).

\section{Discussion}

Using a comprehensive literature review, this systematic review and meta-analysis presented a significant update on the relationship between NSW duration and risk of $\mathrm{BC}$. Based on the overall evaluation of the twenty six articles, in the short-term night-shift workers, the risk of $\mathrm{BC}$ was increased ( $\mathrm{RR}=1.13,95 \% \mathrm{CI}: 1.03-1.24)$, but the increase did not observe in the long-term night-shift workers ( $R R=1.08,95 \%$ CI 0.99-1.17).

\section{Previous meta-analysis of NSW and BC}

The first meta-analysis in this regard was reported in 2005 on six studies, revealing an increase in the risk of $\mathrm{BC}$ among night workers $(\mathrm{RR}=1.51 ; 95 \%, \mathrm{CI}: 1.36-1.68)$ [18]. Erren et al. [31] concluded that the risk of $\mathrm{BC}$ in the shift workers increases by $40 \%$. Following IARC evaluation in 2007, four meta-analyses on BC and NSW were published in 2013 [24, 26, 29, 79]. The results of these studies were contradictory in regards to the effect of NSW on BC. Jia et al. found an overall positive correlation of 1.20 (95\% CI 1.08-1.33; 13 studies) between the risk of $\mathrm{BC}$ and NSW (never versus ever) [26], which is also consistent with the study of Wang et al. [24] and Ijaz et al. [79]. But another review in the same year [29] obtained contradictory results and found no significant association between NSW with increased risk of BC.

Ijaz et al. [79] observed a 9\% risk increase per five years of NSW exposure in case-control studies $(R R=1.09$, 95\% CI: 1.02-1.20), a finding that was not reported in cohort studies [6, 39, 46, 49, 74]. Ijaz et al., due to the low incidence of $\mathrm{BC}$, took both odds ratios (OR) and risk ratios (RR) as valid estimates of the relative risk. So, they reported their results as $R R$, which can be seen in the original article. Travis et al. [28] concluded that NSW, including long-term NSW, has no effect on BC incidence, which is in line with the results of the current study. But He et al. [25] and in later years Yuan et al. [27] reported a significantly positive association between NSW and BC risk. A recent meta-analysis by Dun et al. did not find an overall association between NSW and the risk of BC [30].

However, in Wang et al. study [24], the meta-regression showed a rise of BC risk with the duration of NSW and cumulative night work (pooled $\mathrm{RR}=1.03$, 95\% CI 1.011.05; Pheterogeneity<0.001). In accordance with Wang et al., Yuan et al. mete-analysis showed that the risk of BC is higher in long-term night-shift workers $(\mathrm{OR}=1.316$; 95\% CI1.196-1.448) [27]. These divergent results might be attributed to the different articles included in these meta-analyses. Yuan et al. [27] in their meta-analysis incorporated some articles regarding the effect of LAN and/or sleep disruption on BC. However, the systematic review carried out by Kolstad [19], stated inadequate 
evidence to support the association between NSW and $\mathrm{BC}$, which is inconsistent with the findings of Hansen et al. [80] and Lee et al. [81]. As observed, the results of previous meta-analyses are quite contradictory. According to the results of the present meta-analysis, the risk of BC increases in short-term NSW, while this increase is not obvious in the long-term NSW group. This result differs from studies that reported an increased risk of $\mathrm{BC}$ as the years of NSW increased [24, 27, 79]. It seems that this inconsistency is due to the fact that some meta-analyses have considered ever vs. never NSW, but in the present study, the duration of NSW has been considered.

According to the results of the subgroup meta-analysis, employment in NSW (as short term and long term) do not increase the risk of $\mathrm{BC}$ risk. According to our results and the meta-analyses by Dun et al. [30] and Travis et al. [28], among the groups of nurses, NSW does not increase the risk of $\mathrm{BC}$, which are inconsistent with some previous studies [24, 25, 27]. Significant heterogeneity was observed in our results and some other meta-analyses $[25,27,29,79]$. Generally, the heterogeneity observed in the findings of epidemiological studies can be partially assigned to the large differences in the NSW definition, design of the study, duration of the follow-up period, lefttruncation in cohort studies, lack of chronotype information, social jet lag, and differences in the menopausal status of the population under study as well as subtypes of BC.

Similar to the findings of previous meta-analyses, we also found in the subgroup analysis that the risk of $\mathrm{BC}$ increases in flight attendants, with long or overnight flights $[18,25,29,31]$. However, the role of cosmic radiation as a confounder should not be ignored in this occupational group. Erren et al. suggested a 70\% increase in the risk of $\mathrm{BC}$ in flight attendants [31]. Due to the dearth of studies in relation to this occupational group, further research is needed for more accurate and robust results.

If the analyses were stratified by the study design, the risk of $\mathrm{BC}$ was increased in case-control studies but no increase was seen in cohort studies which is in line with the results reported by Dun et al. [30], He et al. [25] and Ijaz et al. [79]. But our results are inconsistent with the findings of a pooled analysis of case-control studies proposed that $\mathrm{BC}$ risk did not increase with the lifetime duration of night work or with the duration of night shifts in both pre-and post-menopausal women; moreover, the risk might decrease after the cessation of exposure [82]. As a common concern in case-control studies, during the evaluation of night work, recall bias may have been incorporated into our research. This bias is a significant challenge to the validity of self-reported questionnaires when the participants were examined. To remove possible recall bias arising from previous case-control studies on the relationship between NSW and BC, We examined the findings of cohort studies in which effective control of recall bias was possible. There was not an insignificant relationship again. Our subgroup analysis revealed that NSW is related with increasing BC risk in European countries that is in line with some other meta-analyses $[25,30]$. The most important risk of bias in the studies included in the meta-analysis was measurement of exposure which is reported in other studies [79].

The lack of association between long-term NSW and $\mathrm{BC}$ could be due to the healthy worker effect. A healthy worker effect is a special form of selection bias common to occupational cohort studies that occurs because healthy individuals are less likely to be unemployed than are unhealthy individuals $[83,84]$. The main mechanisms for the healthy worker effect in this study are healthbased differential losses to follow up (healthy worker survivor effect), health-based selection of workers in long-term NSW (healthy hire effect) [84].

\section{Strengths and limitations}

One of the strengths of our systematic review and metaanalysis was that in the present study, due to an updated literature search, some recent publications, that were not included in previous meta-analyses, were reviewed [28, $69,71,75]$. From those one study published in 2019 [71] was a large cohort study, and the other reported the findings of three large cohort studies in England [28], which included two cohort reports (one of them only reported "ever" versus "never" NSW). Therefore, we included three cohort studies in two articles. We also incorporated seven studies published from 2013 to 2020 from different countries, one study on nurses [73] with 24 years of follow up (which reported two cohort study: NHS and NHS2), a large cohort study (sister study) that has published recently [75] and four population-based case-control studies [22, 62, 64, 69]; to our knowledge, this is the first time that such studies are included in a meta-analysis based on the duration of NSW. Although the generalizability of our results was enhanced by studies involving larger and more diverse populations, but they adversely increased between-study heterogeneity, which resulted in pooled RRs that were not consistent with previous studies, and more difficult to interpret. Second, several subgroup analyzes were performed to discover whether stratification by study type, occupation, geography, and study design (adequate adjustment for confounders, reproductive factors and family history of $\mathrm{BC}$ ), article's quality category and to report the source of funding are able to minimize the heterogeneity of pooled analyses and suggest expressive associations for the current and future research. Some of the previous meta-analyses incorporated articles concerning the effect of LAN and/ 
or sleep disturbances on $\mathrm{BC}[25,27]$. In these metaanalyses [25, 27], no classifications were done based on the duration of NSW; however, in the present study, the NSW was classified into two categories: short-term and long-term night-shifts. Third, we used several methods (funnel plots, Begg's and Egger's test, trim and fill test) to investigate the publication bias in short-term and longterm exposure groups, separately. The previous metaanalyses did not include the risk of bias assessment [85].

Our study had several limitations. Firstly, considerable variability of study design,, study population, sample size, definition of NSW, mode of exposure quantification, risk estimates, and adjustment for pertinent confounders, may restrict the generalizability of our findings to specific populations. Secondly, our included studies showed various rates of bias, specifically the recall bias associated with self-reported exposures, as seen in many observational studies. Certain included studies (69\%) were designed as (nested) case-control, hence particularly susceptible to recall bias, which can lead to heterogeneity and contradictory results between papers. However, in every study, the authors apply different methods in order to reduce the recall bias, as mentioned previously.. Finally, we might have missed some studies in local languages.

Accordingly, in future studies, exposure must be measured with an objective scale in cohorts with long follow up. In addition, for common confounders, not all studies are obtained or adjusted, further reducing the strength of the exposure-outcome association. It is also recommended that authors focus on the quality of reporting of different sections of articles (especially exposure/ outcome details) and report their articles on the basis of quality assessment tools.

\section{Conclusion}

The present meta-analysis showed a positive statistical relationship between NSW and BC risk in shortterm night-shift workers but no increase was observed in the long-term night-shift workers. Night-shift workers including flight attendants were associated with increased BC risk. Our subgroup analysis revealed that flight attendants with long overnight flights were at an elevated risk of BC. In this case, however, more studies are needed for more robust results. Also, according to the results of the subgroup analysis, the risk of $\mathrm{BC}$ in casecontrol studies adjusted for reproductive factors and family history of $\mathrm{BC}$, as well as studies with high quality were increased in both short term and long term NSW. We recommend that, $\mathrm{BC}$ screening services should be integrated to the routine care for women with night-shift jobs. We suggest further studies with adequate information and exact definition regarding NSW and its duration.

\section{Supplementary Information}

The online version contains supplementary material available at https://doi. org/10.1186/s12905-021-01233-4.

Additional file 1. Funnel plots of the articles performing short and long-term versus never night-work — shift work analysis-Trim and fill test for short and long-term night-shift work-Begg's and Egger's test for publication bias - Risk of bias graph-Quality assessment of included studies-PRISMA checklist

\section{Abbreviations}

IARC: International Agency for Research on Cancer; BC: Breast cancer; NSW: Night-shift work; NOS: Newcastle-Ottawa Scale; LAN: Light at night.

\section{Acknowledgements}

Not applicable.

\section{Authors' contributions}

EM, AT, VGh and RLR were the major contributors to the overall study conception and design. The systemic search of electronic databases was performed by EM and VGh. Studies were screened and critically appraised by EM and VGh. Study elements for extraction were defined by AT, AE and FH and extracted by EM. All authors analyzed and interpreted the data. The manuscript was drafted by EM and revised critically in consultation with all authors. Also, all authors read and approved the final manuscript.

\section{Funding}

The current SR and MA is part of the PhD thesis of the first author approved by Mashhad University of Medical Sciences, Mashhad, Iran, under code of IR.MUMS.NURSEREC.1397.034 (Grant ID: 970008).

\section{Availability of data and materials}

The datasets used and/or analyzed during the current study are available from the corresponding author on reasonable request.

Ethics approval and consent to participate

Not applicable.

\section{Consent for publication}

Not applicable.

\section{Competing interests}

The authors declare that they have no competing interests.

\section{Author details}

${ }^{1}$ Department of Midwifery, School of Nursing and Midwifery, Mashhad University of Medical Sciences, Mashhad, Islamic Republic of Iran. ${ }^{2}$ Department of Epidemiology, School of Health, Mashhad University of Medical Sciences, Mashhad, Islamic Republic of Iran. ${ }^{3}$ Department of Biostatistics, School of Health, Mashhad University of Medical Sciences, Mashhad, Islamic Republic of Iran. ${ }^{4}$ Behavioral Sciences Research Center, Lifestyle Institute, Baqiyatallah University of Medical Sciences, Tehran, Islamic Republic of Iran.

${ }^{5}$ Nursing Faculty, Baqiyatallah University of Medical Sciences, Tehran, Islamic Republic of Iran. ${ }^{6}$ Cancer Research Center, Faculty of Medicine, Mashhad University of Medical Sciences, Mashhad, Islamic Republic of Iran. ${ }^{7}$ Nursing and Midwifery Care Research Center, Mashhad University of Medical Sciences, Mashhad, Islamic Republic of Iran.

Received: 2 September 2020 Accepted: 22 February 2021

Published online: 02 March 2021

References

1. Hirsch BR, Lyman GH. Breast cancer screening with mammography. Curr Oncol Rep. 2011;13(1):63-70. https://doi.org/10.1007/s11912-010-0142-z. 
2. Torre LA, Bray F, Siegel RL, Ferlay J, Lortet-Tieulent J, Jemal A. Global cancer statistics, 2012. CA Cancer J Clin. 2015;65(2):87-108. https://doi. org/10.3322/caac.21262.

3. Pahwa M, Labrèche F, Kim J, Harris MA, Song C, Peters CE, et al. The impact of night shift work on breast cancer: results from the burden of occupational cancer in Canada Study. Am J Ind Med. 2019;62(8):635-42. https://doi.org/10.1002/ajim.22999.

4. Salamanca-Fernández E, Rodríguez-Barranco M, Guevara M, Ardanaz E, Olry ALL, Sánchez M. Night-shift work and breast and prostate cancer risk: updating the evidence from epidemiological studies. An Sist Sanit Navar. 2018;41:211-26.

5. Khakbazan Z, Taghipour A, Roudsari RL, Mohammadi E, Omranipour R. Delayed presentation of self-discovered breast cancer symptoms in Iranian women: a qualitative study. Asian Pac J Cancer Prev. 2014;15(21):9427-32. https://doi.org/10.7314/APJCP.2014.15.21.9427.

6. Schernhammer ES, Kroenke CH, Laden F, Hankinson SE. Night work and risk of breast cancer. Epidemiology. 2006;17:108-11. https://doi. org/10.1097/01.ede.0000190539.03500.c1.

7. NationalSleepfoundation.org. shift work disorder 2019

8. Stevens RG, Hansen J, Costa G, Haus E, Kauppinen T, Aronson KJ, et al. Considerations of circadian impact for defining 'shift work' in cancer studies: IARC working group report. Occup Environ Med. 2011;68(2):9. https:// doi.org/10.1136/oem.2009.053512.

9. Kakouei H, Zamanian Ardakani Z, Karimian S, Ayat Elahi M. Twenty four hours circadian cortisol profile in shift work nurses. Armaghan Danesh. 2009;14(153):47-56.

10. Haus E, Smolensky M. Biological clocks and shift work: circadian dysregulation and potential long-term effects. Cancer Causes Control. 2006;17(4):489-500. https://doi.org/10.1007/s10552-005-9015-4.

11. Blask DE, Hill SM, Dauchy RT, Xiang S, Yuan L, Duplessis T, et al. Circadian regulation of molecular, dietary, and metabolic signalling mechanisms of human breast cancer growth by the nocturnal melatonin signal and the consequences of its disruption by light at night. J Pineal Res. 2011;51(3):259-69. https://doi.org/10.1111/j.1600-079X.2011.00888.x.

12. Parent-Thirion A, Biletta I, Cabrita J, Vargas O, Vermeylen G, Wilczynska A et al. Eurofound: sixth European working conditions survey-overview report (2017 update). Luxembourg: Publications Office of the European Union; 2017.

13. Stevens RG, Brainard GC, Blask DE, Lockley SW, Motta ME. Breast cancer and circadian disruption from electric lighting in the modern world. CA Cancer J Clin. 2014;64(3):207-18.

14. Straif K, Baan R, Grosse Y, Secretan B, El Ghissassi F, Bouvard V, et al. Carcinogenicity of shift-work, painting, and fire-fighting. Lancet Oncol. 2007:8(12):1065-6.

15. Waterhouse J, Buckley P, Edwards B, Reilly T. Measurement of, and some reasons for, differences in eating habits between night and day workers. Chronobiol Int. 2003;20(6):1075-92.

16. Truong T, Liquet B, Menegaux F, Plancoulaine S, Laurent-Puig P, Mulot C, et al. Breast cancer risk, nightwork, and circadian clock gene polymorphisms. Endocr Relat Cancer. 2014;21(4):629-38.

17. Group IMV. Carcinogenicity of night shift work. Lancet Oncol. 2019;20:2. https://doi.org/10.1016/S1470-2045(19)30455-3.

18. Megdal SP, Kroenke CH, Laden F, Pukkala E, Schernhammer ES. Night work and breast cancer risk: a systematic review and meta-analysis. Eur J Cancer. 2005;41(13):2023-32. https://doi.org/10.1016/j.ejca.2005.05.010.

19. Kolstad HA. Nightshift work and risk of breast cancer and other cancers-a critical review of the epidemiologic evidence. Scand J Work Environ Health. 2008:34(1):5-22.

20. Hansen J, Lassen CF. Nested case-control study of night shift work and breast cancer risk among women in the Danish military. Occup Environ Med. 2012;69(8):551-6. https://doi.org/10.1136/oemed-2011-100240.

21. Li W, Ray RM, Thomas DB, Davis S, Yost M, Breslow N, et al. Shift work and breast cancer among women textile workers in Shanghai. China Cancer Causes Control. 2015;26(1):143-50. https://doi.org/10.1007/s1055 2-014-0493-0.

22. Fritschi L, Erren T, Glass D, Girschik J, Thomson A, Saunders C, et al. The association between different night shiftwork factors and breast cancer: a case-control study. Br J Cancer. 2013;109(9):2472-80. https://doi. org/10.1038/bjc.2013.544

23. Lin X, Chen W, Wei F, Ying M, Wei W, Xie X. Night-shift work increases morbidity of breast cancer and all-cause mortality: a meta-analysis of
16 prospective cohort studies. Sleep Med. 2015;16(11):7. https://doi. org/10.1016/j.sleep.2015.02.543.

24. Wang F, Yeung K, Chan W, Kwok C, Leung S, Wu C, et al. A meta-analysis on dose-response relationship between night shift work and the risk of breast cancer. Ann Oncol. 2013;24(11):2724-32. https://doi.org/10.1093/ annonc/mdt283.

25. He C, Anand ST, Ebell MH, Vena JE, Robb SW. Circadian disrupting exposures and breast cancer risk: a meta-analysis. Int Arch Occup Environ Health. 2014:88(5):533-47.

26. Jia Y, Lu Y, Wu K, Lin Q, Shen W, Zhu M, et al. Does night work increase the risk of breast cancer? A systematic review and meta-analysis of epidemiological studies. Cancer Epidemiol. 2013;37(3):197-206.

27. Yuan X, Zhu C, Wang M, Mo F, Du W, Ma X. Night shift work increases the risks of multiple primary cancers in women: a systematic review and meta-analysis of 61 articles. Cancer Epidemiol Prev Biomark. 2018;27(1):25-40.

28. Travis RC, Balkwill A, Fensom GK, Appleby PN, Reeves GK, Wang XS, et al. Night shift work and breast cancer incidence: three prospective studies and meta-analysis of published studies. J Natl Cancer Inst 2016;108(12):djw169.

29. Kamdar BB, Tergas Al, Mateen FJ, Bhayani NH, Oh J. Night-shift work and risk of breast cancer: a systematic review and meta-analysis. Breast Cancer Res Treat. 2013;138(1):291-301.

30. Dun A, Zhao X, Jin X, Wei T, Gao X, Wang Y, et al. Association between night-shift work and cancer risk: updated systematic review and metaanalysis. Front Oncol. 2020;10:1006.

31. Erren TC, Pape HG, Reiter RJ, Piekarski C. Chronodisruption and cancer. Naturwissenschaften. 2008;95(5):367-82.

32. Hartling L, Hamm M, Milne A, Vandermeer B, Santaguida P, Ansari M, Tsertsvadze A, Hempel S, Shekelle P, Dryden D. 2012. Validity and interrater reliability testing of quality assessment instruments. Prepared by the University of Alberta Evidence-based Practice Center under Contract No 290-2007-10021-I) AHRQ Publication No 12-EHC039-EF Rockville, MD: Agency for Healthcare Research and Quality March http://www.effec tivehealthcareahrqgov/reports/finalcfm. 2012

33. GA Wells, B Shea D O'Connell, J Peterson, V Welch, M Losos, P Tugwell. The Newcastle-Ottawa Scale (NOS) for assessing the quality of nonrandomised studies in meta-analyses. http://www.ohri.ca/programs/clini cal_epidemiology/oxford.asp

34. McElvenny DM, Crawford JO, Davis A, Dixon K, Alexander C, Cowie H, et al. A review of the impact of shift-work on occupational cancer: part 1_epidemiological research. Policy Pract Health Saf. 2018;16(1):71-108.

35. Borenstein M, Hedges LV, Higgins JP, Rothstein HR. Introduction to metaanalysis. Hoboken: Wiley; 2011.

36. Higgins JPT, Thomas J, Chandler J, Cumpston M, Li T, Page MJ, Welch VA (eds). Cochrane handbook for systematic reviews of interventions version 6.1 (updated September 2020). Cochrane, 2020. 2020.

37. Egger MDSG, Schneider M, et al. Bias in metaanalysis detected by a simple, graphical test. BMJ Open. 1997;315:629-34.

38. Begg CB, Mazumdar M. Operating characteristics of a rank correlation test for publication bias. Biometrics. 1994;50:1088-101.

39. Schernhammer ES, Laden F, Speizer FE, Willett WC, Hunter DJ, Kawachi I, et al. Rotating night shifts and risk of breast cancer in women participating in the nurses' health study. J Natl Cancer Inst. 2001;93(20):1563-8.

40. Lie J-AS, Kjuus H, Zienolddiny S, Haugen A, Stevens RG, Kjærheim K. Night work and breast cancer risk among Norwegian nurses: assessment by different exposure metrics. Am J Epidemiol. 2011;173(11):1272-9.

41. Lie J-AS, Roessink J. Kjaerheim K Breast cancer and night work among Norwegian nurses. Cancer Causes Control. 2006;17(1):39-44.

42. Datta K, Roy A, Nanda D, Das I, Guha S, Ghosh D, et al. Association of breast cancer with sleep pattern-a pilot case control study in a regional cancer centre in South Asia. Asian Pac J Cancer Prev. 2014;15:8641-5. https://doi.org/10.7314/apjcp.2014.15.20.8641.

43. Pukkala E, Helminen M, Haldorsen T, Hammar N, Kojo K, Linnersjö A, et al. Cancer incidence among Nordic airline cabin crew. Int J Cancer. 2012;131(12):2886-97. https://doi.org/10.1002/ijc.27551.

44. Ren Z. Association of sleep duration, daytime napping, and night shift work with breast cancer risk. AACR. 2014. https://doi.org/10.1158/15387445.AM2014-2181. 
45. Wang P, Ren F-M, Lin Y, Su F-X, Jia W-H, Su X-F, et al. Night-shift work, sleep duration, daytime napping, and breast cancer risk. Sleep Med. 2015;16(4):462-8. https://doi.org/10.1016/j.sleep.2014.11.017.

46. Schwartzbaum J, Ahlbom A, Feychting M. Cohort study of cancer risk among male and female shift workers. Scand J Work Environ Health 2007;33(5):336-43.

47. Reynolds P, Cone J, Layefsky M, Goldberg DE, Hurley S. Cancer incidence in California flight attendants (United States). Cancer Causes Control. 2002;13:317-24. https://doi.org/10.1023/A:1015284014563.

48. Ekpanyaskul C, Sangrajrang S. Cancer incidence among healthcare workers in cancer centers: a 14-year retrospective cohort study in Thailand. Ann Global Health. 2018. https://doi.org/10.29024/aogh.2324.

49. Knutsson A, Alfredsson L, Karlsson B, Åkerstedt T, Fransson El, Westerholm $P$, et al. Breast cancer among shift workers: results of the WOLF longitudinal cohort study. Scand J Work Environ Health. 2013;39:170-7.

50. Vistisen HT, Garde AH, Frydenberg M, Christiansen P, Hansen ÅM, Hansen $J$, et al. Short-term effects of night shift work on breast cancer risk: a cohort study of payroll data. Scand J Work Environ Health. 2017;43(1):5967. https://doi.org/10.5271/sjweh.3603.

51. Arafa A, Eshak ES, Iso H, Muraki I, Tamakoshi A. Night work, rotating shift work and the risk of cancer in Japanese men and women: the JACC study. J Epidemiol. 2020. https://doi.org/10.2188/jea.JE20200208.

52. Bustamante-Montes LP, Flores-Meza B, Hernández-Valero MA, CárdenasLópez A, Dolores-Velázquez R, Borja-Bustamante P, et al. Night shift work and risk of breast cancer in women. Arch Med Res. 2019:50(6):393-9. https://doi.org/10.1016/j.arcmed.2019.10.008.

53. Szkiela M, Kusideł E, Makowiec-Dąbrowska T, Kaleta D. Night shift work - a risk factor for breast cancer. Int J Environ Res Public Health. 2020;17(2):659. https://doi.org/10.3390/ijerph17020659.

54. Yang W, Shi Y, Ke X, Sun H, Guo J, Wang X. Long-term sleep habits and the risk of breast cancer among Chinese women: a case-control study. Eur J Cancer Prev. 2019;28(4):323-9. https://doi.org/10.1097/CEJ.0000000000 000458.

55. Tynes T, Hannevik M, Andersen A, Vistnes Al, Haldorsen T. Incidence of breast cancer in Norwegian female radio and telegraph operators. Cancer Causes Control. 1996;7(2):197-204. https://doi.org/10.1097/CEJ.00000 00000000458

56. Rafnsson VSP, Tulinius $H$, Hrafnkelsson J. Breast cancer risk in airline cabin attendants: a nested case-control study in Iceland. Occup Environ Med. 2003:60(11):807-9. https://doi.org/10.1136/oem.60.11.807.

57. Linnersjö AHN, Dammström B, Johansson M, Eliasch H. Cancer incidence in airline cabin crew: experience from Sweden. Occup Environ Med. 2003;60(11):810-4. https://doi.org/10.1136/oem.60.11.810.

58. Hansen JS, Richard G. Case-control study of shift-work and breast cancer risk in Danish nurses: impact of shift systems. Eur J Cancer. 2012;48(11):1722-9. https://doi.org/10.1016/j.ejca.2011.07.005.

59. Menegaux F, Truong T, Anger A, Cordina-Duverger E, Lamkarkach F, Arveux P, et al. Night work and breast cancer: a population-based casecontrol study in France (the CECILE study). Int J Cancer. 2013;132(4):92431. https://doi.org/10.1002/ijc.27669.

60. O'leary ES, Schoenfeld ER, Stevens RG, Kabat GC, Henderson K, Grimson $\mathrm{R}$, et al. Shift work, light at night, and breast cancer on Long Island. New York Am J Epidemiol. 2006;164(4):358-66. https://doi.org/10.1093/aje/ kwj211.

61. Hansen J. Increased breast cancer risk among women who work predominantly at night. Epidemiology. 2001;12(1):74-7.

62. Grundy A, Richardson H, Burstyn I, Lohrisch C, SenGupta SK, Lai AS, et al. Increased risk of breast cancer associated with long-term shift work in Canada. Occup Environ Med. 2013;70(12):831-8. https://doi.org/10.1136/ oemed-2013-101482

63. Davis S, Mirick DK, Stevens RG. Night shift work, light at night, and risk of breast cancer. J Natl Cancer Inst. 2001;93(20):1557-62. https://doi. org/10.1093/jnci/93.20.1557.

64. Papantoniou K, Castaño-Vinyals G, Espinosa A, Aragonés N, Pérez-Gómez $B$, Ardanaz E, et al. Breast cancer risk and night shift work in a case-control study in a Spanish population. Eur J Epidemiol. 2016;31(9):867-78. https://doi.org/10.1007/s10654-015-0073-y.

65. Pesch B, Harth V, Rabstein S, Baisch C, Schiffermann M, Pallapies D, et al. Nightwork and breast cancer-results from the German GENICA study. Scand J Work Environ Health. 2010;36:134-41.
66. Rabstein S, Harth V Pesch B, Pallapies D, Lotz A, Justenhoven C, et al. Night work and breast cancer estrogen receptor status - results from the German GENICA study. Scand J Work Environ Health. 2013;39:448-55.

67. Santi SA, Meigs ML, Zhao Y, Bewick MA, Lafrenie RM, Conlon MS. A case-control study of breast cancer risk in nurses from Northeastern Ontario, Canda. Cancer Causes Control. 2015;26(10):1421-8. https://doi. org/10.1007/s10552-015-0633-1.

68. Lie J-AS, Kjuus H, Zienolddiny S, Haugen A, Kjærheim K. Breast cancer among nurses: is the intensity of night work related to hormone receptor status? Am J Epidemiol. 2013;178(1):110-7. https://doi.org/10.1093/aje/ kws428.

69. Pham T-T, Hwang M, Lee E-S, Kong S-Y, Jung S-Y, Lee S, et al. Nightshift work and risk of breast cancer in Korean women. Clin Epidemiol. 2019;11:743. https://doi.org/10.2147/CLEP.S199521.

70. Åkerstedt T, Knutsson A, Narusyte J, Svedberg P, Kecklund G, Alexanderson K. Night work and breast cancer in women: a Swedish cohort study. BMJ Open. 2015;5(4):e008127

71. Jones ME, Schoemaker MJ, McFadden EC, Wright LB, Johns LE, Swerdlow AJ. Night shift work and risk of breast cancer in women: the Generations Study cohort. Br J Cancer. 2019. https://doi.org/10.1038/s4141 6-019-0485-7.

72. Koppes LL, Geuskens GA, Pronk A, Vermeulen RC, De Vroome EM. Night work and breast cancer risk in a general population prospective cohort study in the Netherlands. Eur J Epidemiol. 2014;29(8):577-84. https://doi. org/10.1007/s10654-014-9938-8.

73. Wegrzyn LR, Tamimi RM, Rosner BA, Brown SB, Stevens RG, Eliassen $\mathrm{AH}$, et al. Rotating night-shift work and the risk of breast cancer in the nurses' health studies. Am J Epidemiol. 2017;186(5):532-40. https://doi. org/10.1093/aje/kwx140.

74. Pronk A, Ji B-T, Shu X-O, Xue S, Yang G, Li H-L, et al. Night-shift work and breast cancer risk in a cohort of Chinese women. Am J Epidemiol. 2010;171(9):953-9.

75. Sweeney MR, Sandler DP, Niehoff NM, White AJ. Shift work and working at night in relation to breast cancer incidence. Cancer Epidemiol Prev Biomark. 2020;29(3):687-9. https://doi.org/10.1158/1055-9965.EPI-19-1314.

76. US Department of Labor Bureau of Statistics Staff. Occupational outlook handbook. 2000. Bernan Press (PA).

77. Duval S, Tweedie R. A nonparametric "trim and fill" method of accounting for publication bias in meta-analysis. J Am Stat Assoc. 2000a;95(449):89_ 98. https://doi.org/10.1080/01621459.2000.10473905.

78. Duval S, Tweedie R. Trim and fill: a simple funnel-plot-based method of testing and adjusting for publication bias in meta-analysis. Biometrics. 2000b;56(2):455-63. https://doi.org/10.1111/j.0006-341X.2000.00455.x.

79. Ijaz SVJ, Seidler A, Lindbohm MLA, Orsini N, et al. Night-shift work and breast cancer - a systematic review and meta-analysis. Scand J Work Environ Health. 2013;39:431-47.

80. Hansen J. Night shift work and risk of breast cancer. Curr Environ Health Rep. 2017:4(3):325-39.

81. Lee H-E, Lee J, Jang T-W, Kim I-A, Park J, Song J. The relationship between night work and breast cancer. Ann Occup Environ Med. 2018;30(1):11 https://doi.org/10.1186/s40557-018-0221-4

82. Cordina-Duverger E, Menegaux F, Popa A, Rabstein S, Harth V, Pesch B, et al. Night shift work and breast cancer: a pooled analysis of populationbased case-control studies with complete work history. Berlin : Springer; 2018. https://doi.org/10.1007/s10654-018-0368-x.

83. Chowdhury R, Shah D, Payal AR. Healthy worker effect phenomenon: revisited with emphasis on statistical methods - a review. Indian J Occup Environ Med. 2017;21(1):2. https://doi.org/10.4103/ijoem.IJOEM_53_16.

84. Pearce N, Checkoway H, Kriebel D. Bias in occupational epidemiology studies. Occup Environ Med. 2007;64(8):562-8. https://doi.org/10.1136/ oem.2006.026690.

85. Pahwa M. Night shift work and breast cancer risk: what do the metaanalyses tell us? Scand J Work Environ Health. 2018;44(4):432-5. https:// doi.org/10.5271/sjweh.3738.

\section{Publisher's Note}

Springer Nature remains neutral with regard to jurisdictional claims in published maps and institutional affiliations. 